\title{
Understanding Local Water Collaboration for the Potential to Enhance Community Source Water Protection at Chippewas of the Thames First Nation
}

\author{
Natalya Garrod - MSc Thesis Research \\ Rural Planning and Development, University of Guelph \\ Rural Symposium OMAFRA
}

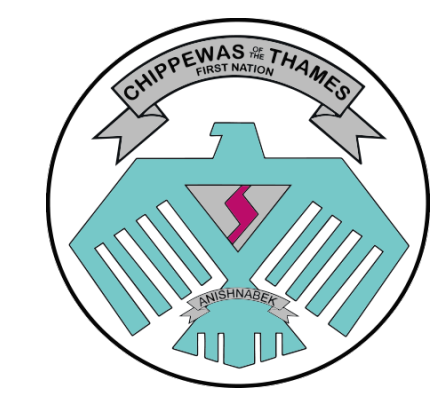


To understand how collaboration between

\section{Research Goal} local water actors (municipalities and conservation authorities) can support First Nations community-level source water protection 


\section{The Problem}

First Nations communities in Canada chronically lack water security

January 2021: 57 long-term drinking water advisories on First Nations communities in Canada

First Nations face higher rates of water insecurity as compared to non-First Nations communities in Canada

First Nation water is under Federal jurisdiction. First Nations have limited involvement in off-reserve water upstream of them which, calls for collaboration. 


\section{What is the research about?}

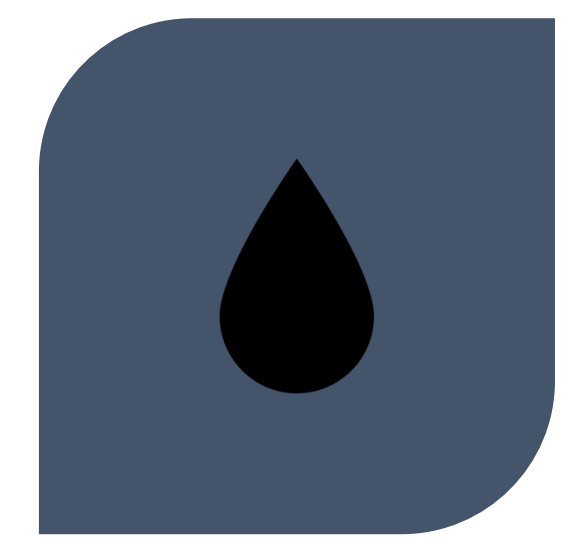

WATER GOVERNANCE

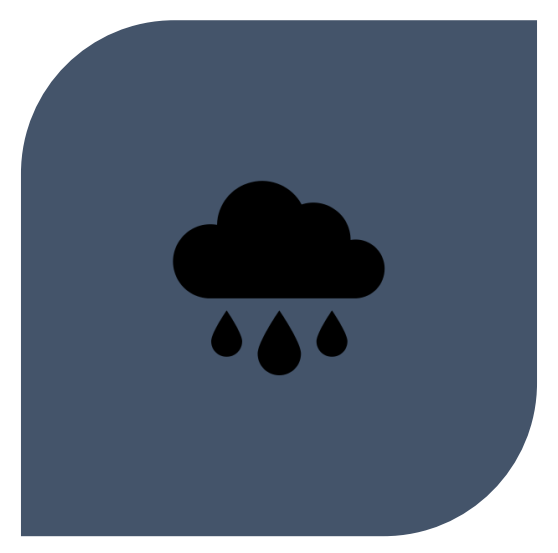

SOURCE WATER PROTECTION

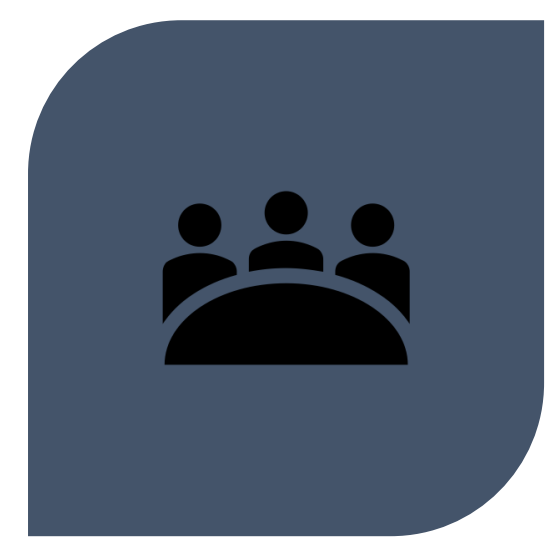

COLLABORATION 
What stakeholders were engaged?

- Chippewas of the Thames First Nations

- City of London

- Lower Thames Conservation Authority

- St. Clair Conservation Authority

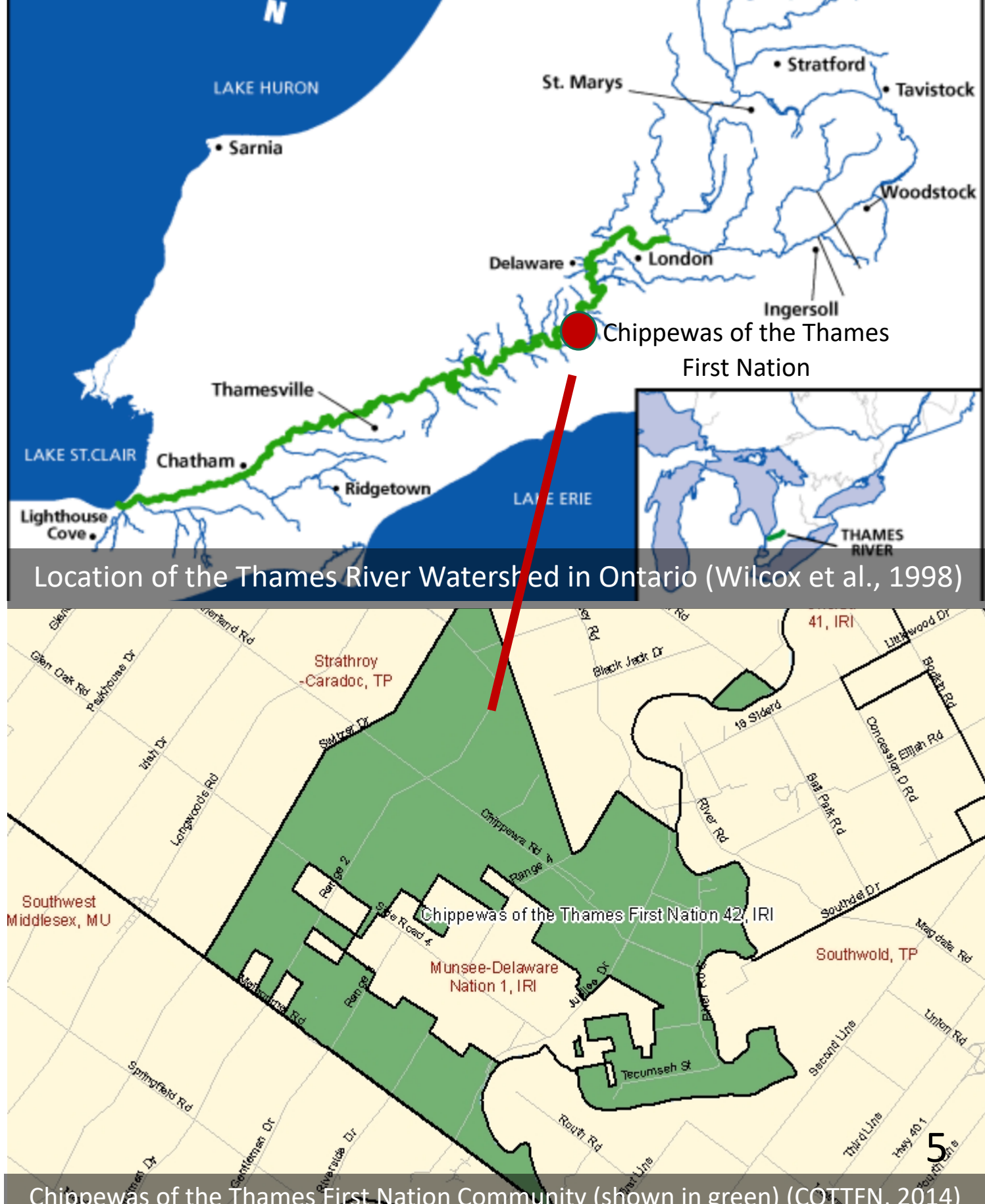




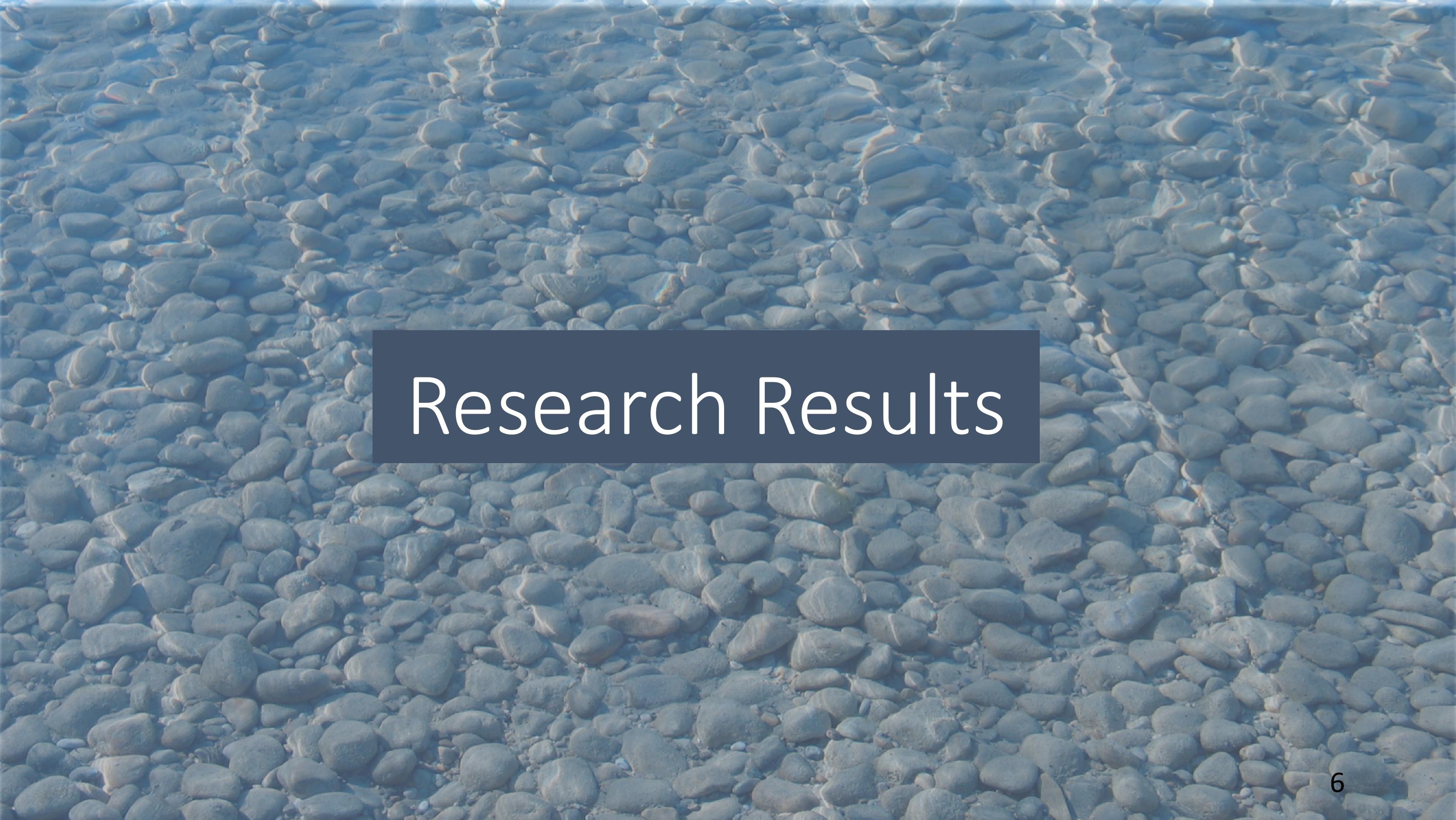




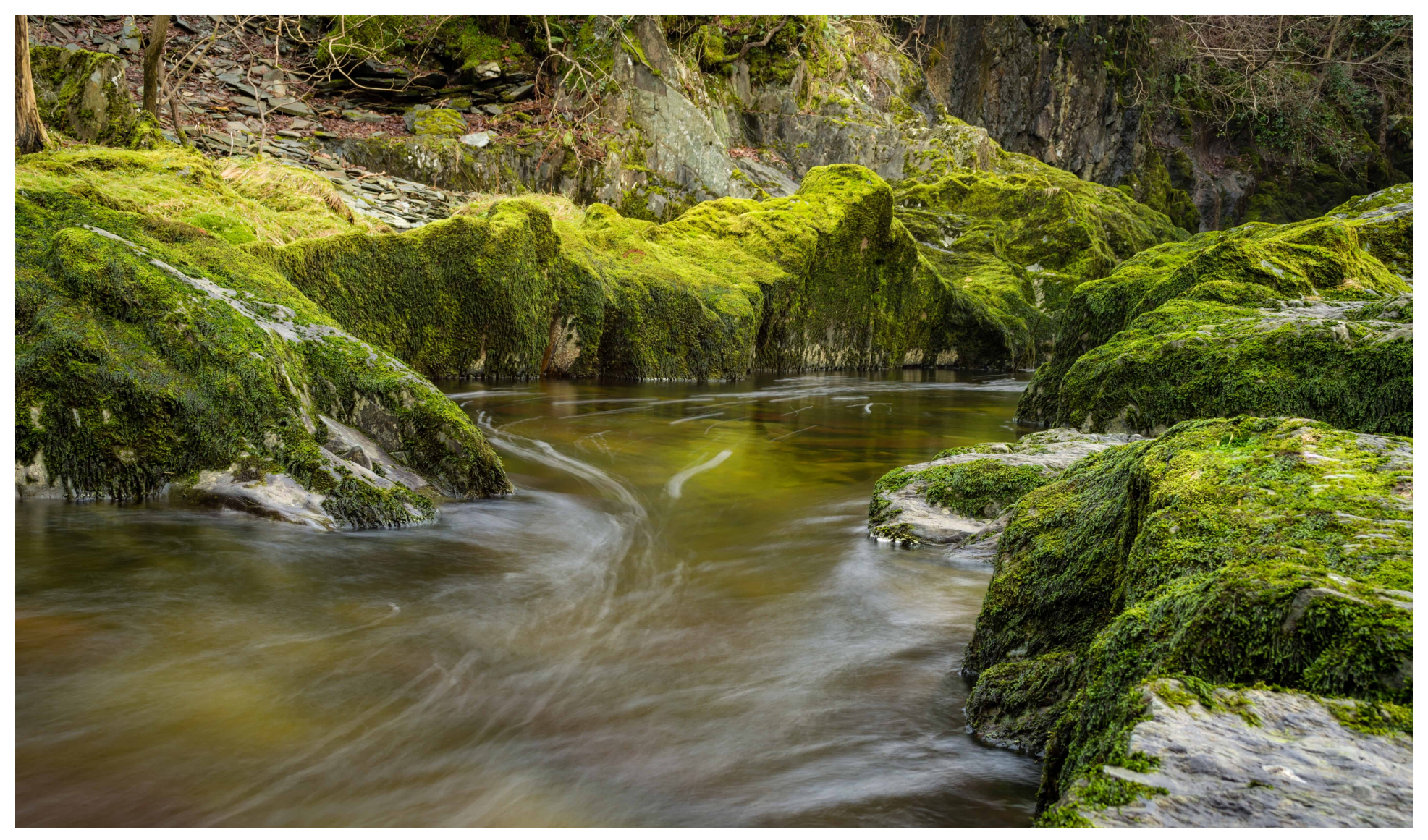

1. Understanding and Respecting One Another

2. Finding Commonalities

3. Agreeing on a Resolution

4. Working Together

5. Decisions that are Consistent with Each Party's Mandate

6. Commitment to Collaboration

Perspectives of Water Actors

7. Good Dialogue

Towards Collaboration 
Barriers to Water Collaboration

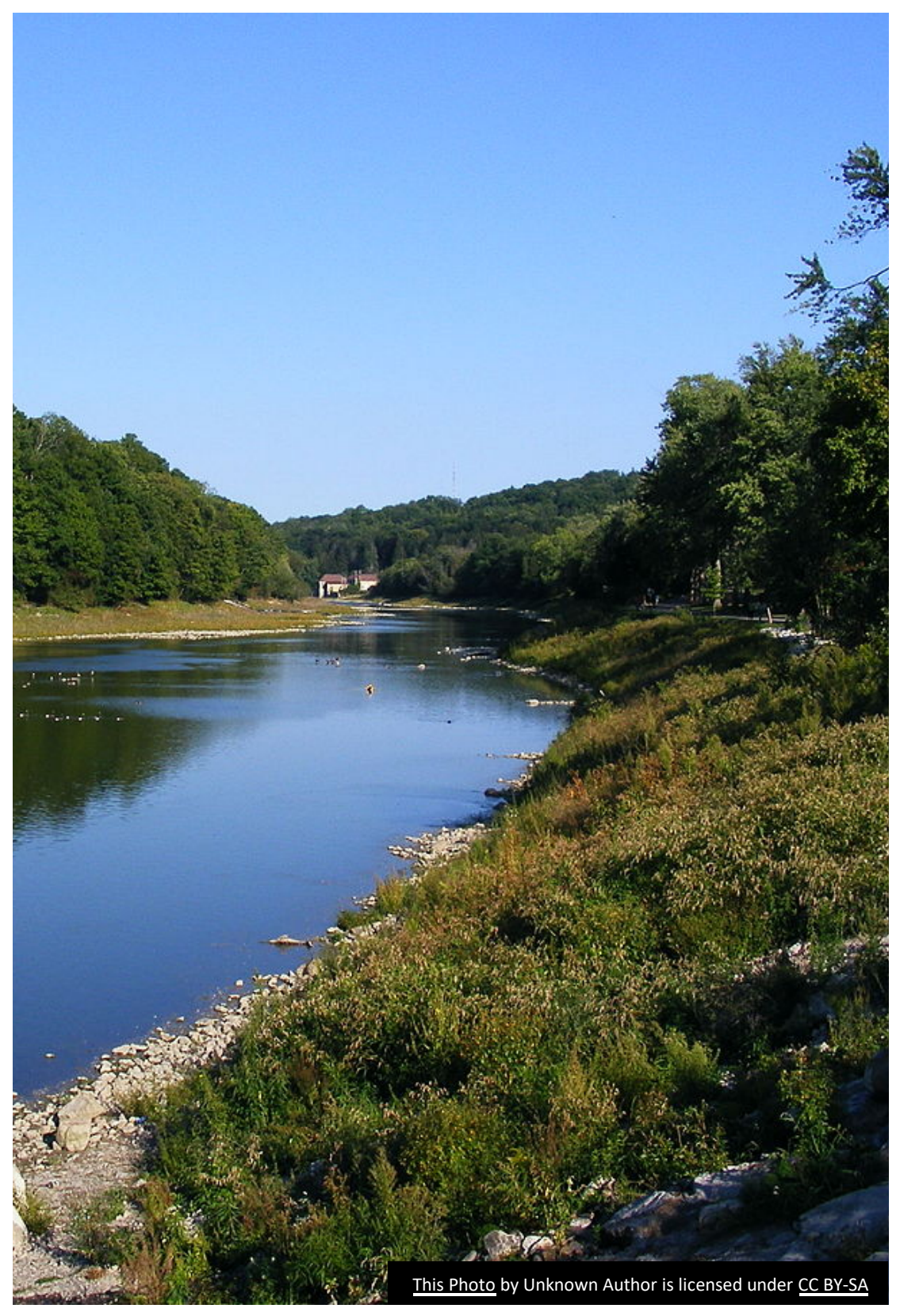

1. Competing priorities

2. Perspectives of collaboration

3. Budgeting for collaboration

4. Navigating governance structures and uncertainty

5. Lack of impetus to collaborate

6. Historical mistrust 


\section{Takeaways}

Sharing the Thames River means caring for the health and well-being of the river. When we secure ecosystem health, we create water security for humans. This involves building strong relationships and upholding responsibilities to the river. 
Visit a reserve and build relationships with local First Nations

Learnt to think critically and analyze research results

Exposure to different careers/potential employment opportunities

\section{Impacts of the project on myself}




\section{Acknowledgements}

Chippewas of the Thames First Nation Anishinaabeg of the territory of Deshkan Ziibing

\section{Research Contributors}

Emma Young, Senior Environment Officer (community contact)

Dr Sheri Longboat, graduate advisor, University of Guelph

Dr Jana Levison, committee member, University of Guelph

Social Sciences and Humanities Research Council

Ministry of Agriculture, Food, and Rural Affairs for providing me the opportunity to present my research

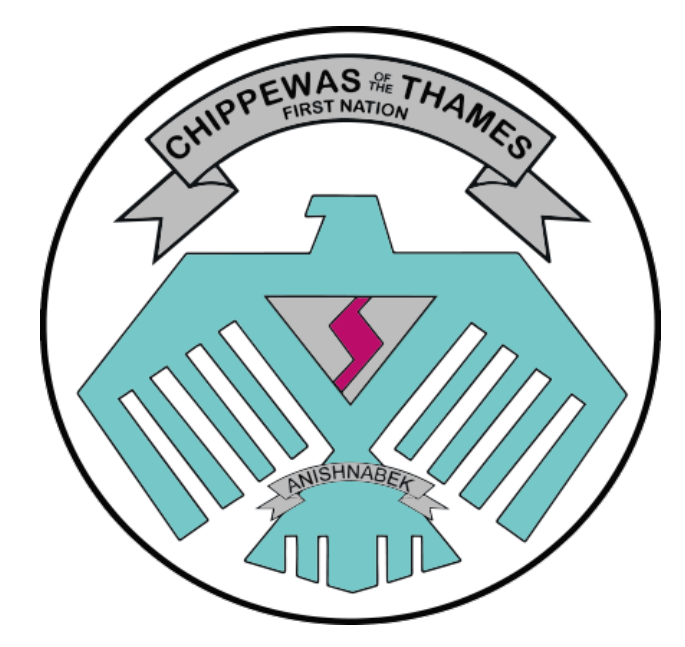

Social Sciences and Humanities Research Council of Canada 


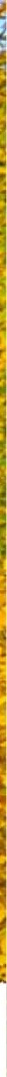

Thank You • Miigwetch

Questions?
Natalya Garrod

ngarrod@uoguelph.ca University of Guelph 


\section{References}

Patrick, R., Grant, K., Bharadwaj, L. (2019). Reclaiming Indigenous Planning as a Pathway to Local Water Security. Water. $11(5), 936$.

Melnychuk, N., De Loë, R., \& University of Waterloo. School of Environment, Resources Sustainability. (2017). Assessing legitimacy within collaborative water governance: How, when, and by whom? Waterloo, Ontario, Canada: University of Waterloo.

Longboat, S., \& Wilfrid Laurier University. Faculty of Graduate Studies. Dept. of Geography. (2012). First Nation water security and collaborative governance : Chippewas of Kettle and Stony Point First Nations, Ontario, Canada (Canadian theses on microfiche ; NR-94195). Waterloo, Ont.: Wilfrid Laurier University.

McGregor, D. (2012). Traditional Knowledge: Considerations for protecting water in Ontario. The International Indigenous Policy Journal, 3(11), 1-23.

Ivey, J., de Loe, R. Kreutzwiser, R., Ferreyra, C. (2006a). An Institutional Perspective on Local Capacity for Source Water Protection. Geoforum. 37(6), 944-957.

Government of Canada (2020). Ending long-term drinking water advisories. Indigenous Services Canada. Ottawa, ON. Retrieved from https://www.canada.ca/en/indigenous-services-canada/news/2019/09/monthlyprogress-update-through-august-2019-on-drinking-water-advisories-on-public-systems-on-reserves.html 